\title{
QUALIDADE MICROBIOLÓGICA DE ÁGUA MINERAL COMERCIALIZADA EM GALÕES DE 20 LITROS E DE POÇOS ARTESIANOS NO MUNICÍPIO DE FRUTAL/MG
}

\author{
MARTINS, Heytor Lemos ${ }^{1}$ \\ MACHADO, Giovanna Carla de Lima ${ }^{1}$ \\ MARTINS, Eduardo da Silva ${ }^{1}$
}

\begin{abstract}
RESUMO: Nos últimos anos, a população vem consumindo cada vez mais água mineral, buscando praticidade e segurança. Há também uma tendência de construção de muitos poços artesianos, tanto em residências quanto nas empresas, visando, além de tentar garantir o abastecimento, diminuir os gastos com água, como está ocorrendo no município de Frutal/MG. Porém, a água mineral comercializada em garrafas plásticas e galões não está isenta da possibilidade de contaminação, dependendo da forma de sua coleta, envase e manipulação. Água proveniente de poços pode também estar contaminada, o que leva riscos a quem a consome. O objetivo deste estudo foi avaliar a qualidade da água mineral em galões de 20 litros e de poços artesianos no município de Frutal/MG, por meio da determinação de coliformes termotolerantes. Foram coletadas 30 amostras de água mineral em galões e 30 amostras de poços artesianos. A determinação de coliformes termotolerantes foi feita com meio de cultura A1, em séries múltiplas de 5 tubos de ensaio contendo tubos de Durhan. Dentre as 30 amostras de água mineral em galões de 20L, $3(10 \%)$ estavam em desacordo com a legislação para coliformes termotolerantes. Dentre as amostras de água de poços artesianos, 9 (30\%) estavam fora dos padrões exigidos pela legislação vigente, que estabelece ausência deste grupo de micro-organismos. Nas amostras contaminadas por coliformes termotolerantes, há o risco do consumo da água, uma vez que indicam a presença de microrganismos patogênicos.
\end{abstract}

Palavras-chave: Coliformes termotolerantes. Água. Qualidade da água.

SUMMARY: In recent years, the population has been consuming increasingly mineral water, seeking practicality and safety. There is also a trend of construction of many artesian wells, both in homes and companies, aiming, besides trying to guarantee the supply, to reduce the expenses with water, as it is occurring in the city of Frutal/MG. However, mineral water marketed in plastic bottles and gallons is not exempt from the possibility of contamination, depending on the form of its collection, packaging and handling. Water from the artesian wells may also be contaminated, which carries risks to the user. The objective of this study was to evaluate the quality of mineral water in gallons of 20 liters and artesian wells in the city of Frutal/MG, by means of the determination of thermotolerant coliforms. Thirty samples of mineral water in gallons and 30 samples of artesian wells were collected. The determination of thermotolerant coliforms was done with A1 culture medium, in multiple series of 5 test tubes containing Durhan tubes. Of the 30 mineral water samples in 20L gallons, $3(10 \%)$ were in disagreement with the legislation for thermotolerant coliforms. Among the water samples from artesian wells, $9(30 \%)$ were outside the standards required by current legislation, which establishes absence of this group of microorganisms. In samples contaminated by thermotolerant coliforms, there is the risk of water consumption, since they indicate the presence of pathogenic microorganisms.

Keywords: Thermotolerant coliforms. Water. Water quality.

\section{INTRODUÇÃO}

A água é um recurso natural indispensável à vida. É essencial à produção de alimentos, desenvolvimento econômico e promoção social. Porém, a água com má qualidade pode trazer riscos à

\footnotetext{
${ }^{1}$ Universidade do Estado de Minas Gerais
} 
saúde, servindo de veículo para vários agentes biológicos e químicos (KASELANI, 2017).

Além de ser um importante veículo de transmissão de agentes patológicos, a água pode ser também uma fonte de contaminação por produtos químicos. Aproximadamente $82 \%$ da população mundial não tem acesso à água potável de qualidade. Decorrente disso, anualmente, mais de cinco milhões de pessoas morrem por adquirirem doenças relacionadas à água. Mundialmente, estima-se que 88\% das mortes por diarreia estão associadas a doenças de transmissão (GROTT et al., 2016). A preocupação com a qualidade da água, decorrente da progressiva poluição hídrica, é um dos motivos que levam grande parte da população ao consumo de água proveniente de fontes minerais (LECLERC; MOREAU, 2002).

Levantamentos de entidades do setor de água mineral engarrafada apontam para um franco crescimento da indústria de água mineral e potável de mesa, que hoje se apresenta como um dos mais favoráveis mercados de investimento no setor mineral brasileiro. O conceito de pureza associada à água mineral é, também, responsável por seu aumento de consumo, porém não se tem certeza sobre a superioridade desta em relação à água de abastecimento público (PONTARA et al., 2011).

Mesmo assim, com a dúvida sobre a qualidade da água de abastecimento público, o cidadão passou a utilizar a água mineral com maior intensidade. Para atender a esse aumento na demanda as indústrias aumentaram a produção. Novas empresas surgiram, mas também o comércio ilegal. Assim, é necessário conhecer se a qualidade esperada e paga pelo consumidor nesse produto, realmente existe (SABIONI; SILVA, 2006).

Em relação aos micro-organismos presentes na água mineral, Pontara et al. (2011) afirmam que a percepção de que a água mineral é segura e isenta de impurezas deve ser repensada, sendo necessário avaliar critérios de monitoramento e análise microbiológica. A população em geral considera a água mineral segura, mas não existem estudos que comprovem esta hipótese para a maioria das cidades brasileiras.

Um dos principais indicadores de qualidade microbiológica da água é o grupo dos coliformes. É definido pelo Standard Methods for the Examination of Water and Wastewater (APHA, 2005) como "todas as bactérias aeróbias ou anaeróbias facultativas, gram negativas, não esporuladas e na forma de bastonete", as quais fermentam a lactose com formação de gás dentro de $48 \mathrm{~h}$ a $35^{\circ} \mathrm{C}$ (coliformes totais) ou a $45^{\circ} \mathrm{C}$ (coliformes termotolerantes ou fecais). A presença de coliformes termotolerantes em água potável é um dos melhores indicadores de que existe risco a saúde do consumidor (SCHURACCHIO, 2010).

Diante do contexto, nas áreas urbanas muitos recorrem à compra de água mineral em galões, buscando qualidade e segurança no consumo. Outros, tanto em áreas urbanas quanto rurais, recorrem à perfuração de poços artesianos, tanto para uso geral, quanto para consumo humano. Esse fato é comum no município de Frutal/MG, onde muitos moradores perfuram poços, principalmente devido ao alto custo da água tratada. Assim, o presente trabalho teve como objetivo avaliar a qualidade microbiológica da água mineral engarrafada em galões de 20 litros e também da água proveniente de poços artesianos no município de Frutal/MG, visando estabelecer se há riscos microbiológicos derivados do seu consumo.

\section{MATERIAL E MÉTODO}

\section{Coleta e preparação das amostras}

Foram coletadas 30 amostras ( 5 amostras mensais, durante 6 meses) de água proveniente de poços artesianos, tanto na cidade quanto em propriedades rurais, e 30 amostras, também durante 6 meses, de água mineral engarrafada (de galões de 20 litros) em supermercados e locais de vendas de bebidas de 
Frutal, município localizado no Estado de Minas Gerais, na divisa com o Estado de São Paulo (Figura 1). De cada local, foram adquiridas uma ou mais amostras, coletadas aleatoriamente.

Figura 1: Município de Frutal/MG, onde foram feitas as coletas.

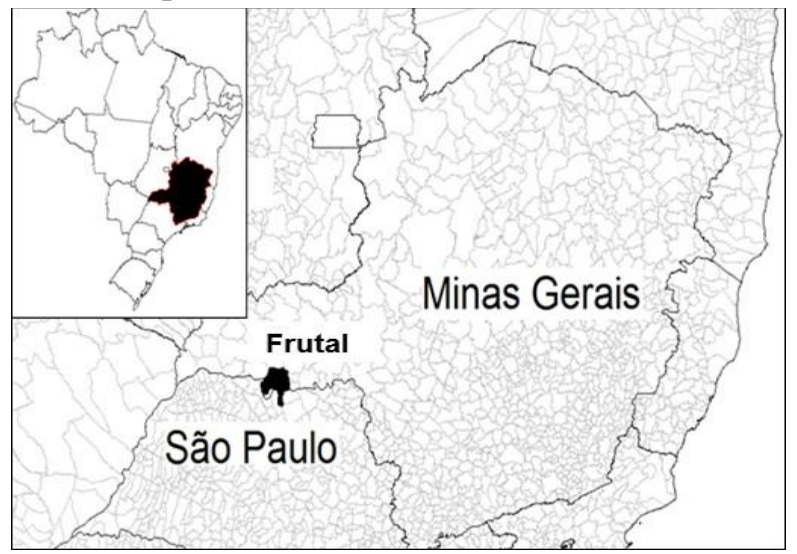

Fonte: arquivo pessoal.

No momento da coleta das águas provenientes de poços artesianos, foi feita desinfecção do local de saída, com álcool etílico $70 \%$, e a água coletada em frascos previamente esterilizados. Para a água envasada em galões de $20 \mathrm{~L}$, foram observadas as validades do galão e da água envasada, e foi feita sua higienização externa e a assepsia da parte superior do galão (gargalo e base do gargalo) com álcool etílico $70 \%$. No momento da abertura do galão, realizou-se nova assepsia na tampa com álcool $70 \%$ e o lacre foi cortado com lâmina flambada.

As amostras foram transportadas em caixa de isopor, contendo cubos de gelo, até o Laboratório de Microbiologia da Universidade do Estado de Minas Gerais (UEMG, campus de Frutal), sendo mantidas sob refrigeração até o momento das análises microbiológicas, as quais foram realizadas no máximo em 2 horas. As embalagens foram desinfetadas com álcool a 70\% iodado antes de serem abertas.

\section{Determinação de coliformes termotolerantes}

A determinação de coliformes termotolerantes foi feita com meio de cultura A1, em séries múltiplas de 5 tubos de ensaio contendo tubos de Durham, conforme CETESB (L5.406, de junho de 2007). As diluições $\left(10^{-1}\right.$ a $\left.10^{-3}\right)$ foram feitas transferindo $10 \mathrm{ml}$ da água coletada para tubos contendo $90 \mathrm{ml}$ de água destilada esterilizada, tendo assim a diluição $10^{-1}$, e assim sucessivamente para as outras diluições.

Após a inoculação de todos os volumes da amostra ou das diluições requeridas para o ensaio, foi efetuada uma pré-incubação a $35^{\circ} \mathrm{C} \pm 0,5^{\circ} \mathrm{C}$ de todos os tubos inoculados, durante 3 horas. Após esse período, os tubos de ensaio foram transferidos para um banho-maria ou incubadora a $44,5^{\circ} \mathrm{C} \pm 0,2^{\circ} \mathrm{C}$, para a continuidade da incubação durante $21 \pm 2$ horas, conforme metodologia estabelecida para o meio A1. Foram considerados resultados positivos para o teste, todos os tubos que apresentarem formação de gás no tubo de Durham. Com os dados obtidos, foi calculado o Número Mais Provável (NMP) de coliformes termotolerantes em $100 \mathrm{~mL}$ da amostra, através da tabela de Hoskins.

Os resultados foram expressos em Número Mais Provável (NMP) de coliformes termotolerantes/100 mL de água e comparados de acordo com a RDC 275/2005 (BRASIL, 2005) e Portaria MS No 2914 (BRASIL, 2011), que estabelecem que a água para consumo humano deve estar ausente de coliformes termotolerantes. 


\section{RESULTADO}

Tanto a RDC/275 (BRASIL, 2005) quanto a Portaria 2914/2011 (BRASIL, 2011) preconizam a ausência de coliformes termotolerantes $/ 100 \mathrm{~mL}$ de água como padrão microbiológico para este indicador em amostras de água mineral engarrafadas e naquelas provenientes de poços artesianos.

Dentre as 30 amostras de água mineral engarrafadas em galões de $20 \mathrm{~L}$ avaliadas, 3 (10\% do total) estavam em desacordo com a legislação vigente (Tabela 1).

Tabela 1: Determinação de coliformes termotolerantes nas amostras de água mineral engarrafadas em galões de 20L.

\begin{tabular}{cc}
\hline Amostras & Coliformes Termotolerantes (NMP/100mL) * \\
\hline $\mathbf{1}$ a 20 & $<1,8$ \\
$\mathbf{2 1}$ & 230 \\
$\mathbf{2 2}$ & 2400 \\
\hline $\mathbf{2 3}$ a 25 & $<1,8$ \\
\hline $\mathbf{2 6}$ & 45 \\
$\mathbf{2 7}$ a 30 & $<1,8$ \\
\hline
\end{tabular}

* O valor de NMP/100 mL < 1,8 refere-se à quando todos os tubos na diluição utilizada forem negativos para a presença de coliformes termotolerantes, de acordo com a tabela de NMP (CETESB, 2007).

Alguns trabalhos na literatura destacam contaminação de amostras de água mineral engarrafadas em galões de $20 \mathrm{~L}$, comercializadas em diferentes localidades. Coelho et al. (2010), também relatou o índice de 10\% de contaminação de água mineral comercializada em galões de 20 litros, em amostras avaliadas em Recife (PE). Resultado semelhante foi relatado por Farache Filho e Dias (2008), no qual 9,5\% das amostras de água mineral comercializadas nas cidades de Araraquara e Américo Brasiliense (SP) estavam com presença de coliformes termotolerantes.

Já no trabalho descrito por Gusmão (2014), nenhuma amostra de água avaliada em Vitória da Conquista (BA) estava contaminada por coliformes termotolerantes, estando assim nos padrões para consumo humano, em relação a esse indicador.

A presença de coliformes termotolerantes na água indica sua contaminação por bactérias patogênicas de origem entérica, tais como Campylobacter, Helicobacter e Legionella. A contaminação da água por bactérias de origem intestinal também pode ser um indicativo da presença de outros grupos de microrganismos patogênicos, tais como vírus, protozoários e helmintos (AL HARBI, 2003).

Com relação às amostras de água provenientes de poços artesianos avaliadas, 9 (30\% do total) estavam em desacordo com a legislação vigente, que estabelece ausência de coliformes termotolerantes em água para consumo humano (Tabela 2). 
Tabela 2: Determinação de coliformes termotolerantes nas amostras de água provenientes de poços artesianos do município de Frutal/MG.

\begin{tabular}{cc}
\hline Amostras & Coliformes Termotolerantes $(\mathbf{N M P / 1 0 0 m L}) *$ \\
\hline $\mathbf{1}$ a 20 & $<1,8$ \\
$\mathbf{2 1}$ & 490 \\
$\mathbf{2 2}$ & 490 \\
$\mathbf{2 3}$ & 700 \\
$\mathbf{2 4}$ & 490 \\
$\mathbf{2 5}$ & 700 \\
\hline $\mathbf{2 6}$ & $<1,8$ \\
$\mathbf{2 7}$ & 2400 \\
\hline $\mathbf{2 8}$ & 45 \\
$\mathbf{2 9}$ & 130 \\
$\mathbf{3 0}$ & 20 \\
\hline
\end{tabular}

* $\mathrm{O}$ valor de $\mathrm{NMP} / 100 \mathrm{~mL}<1,8$ refere-se à quando todos os tubos na diluição utilizada forem negativos para a presença de coliformes termotolerantes, de acordo com a tabela de NMP (CETESB, 2007).

Alguns trabalhos também descrevem índices de contaminação de águas provenientes de poços artesianos, em várias localidades. Resultados relatados por Costa et al. (2012) mostraram que 12,2\% das amostras de água de poços artesianos do Estado do Ceará estavam contaminadas por coliformes termotolerantes. Oliveira e Parussolo et al. (2014) relataram que 20\% das amostras de água de poços em propriedades rurais do município de Campo Mourão (PR) também estavam contaminadas por coliformes termotolerantes, sendo, assim, impróprias para o consumo humano.

Colvara, Lima e Silva (2009) avaliaram as características bacteriológicas de 20 amostras de água subterrânea em poços artesianos de cinco municípios do sul do Rio Grande do Sul, e encontraram um elevado índice de contaminação, uma vez que $70 \%$ estavam contaminadas com coliformes termotolerantes, demonstrando qualidade sanitária deficiente dessa água e refletindo o risco associado ao consumo de água proveniente destes poços artesianos.

As possíveis causas da contaminação em algumas amostras de água no presente trabalho feito no município de Frutal/MG são a presença de fossas sépticas em pontos de coleta nas propriedades rurais onde não há rede coletora de esgoto, e as atividades agropecuárias, das quais podem surgir resíduos de fezes de animais, contaminando a água com microrganismos intestinais como os coliformes termotolerantes.

\section{CONCLUSÃO}

A maioria das amostras de água mineral engarrafadas estava dentro dos padrões da legislação em relação à presença de coliformes termotolerantes, mas a presença de amostras impróprias é preocupante, uma vez que são comercializadas como não apresentando riscos microbiológicos, ou seja, em desacordo com a legislação vigente.

A ocorrência de coliformes termotolerantes em 30\% das amostras de água provenientes de poços artesianos avaliadas demonstra que nestes locais a água estava imprópria para o consumo humano. Os resultados sugerem a necessidade de um monitoramento e estudo das causas da contaminação da água naquelas 
propriedades que utilizam os poços artesianos como fonte de água para o consumo humano, visando minimizar os riscos de sua utilização.

\section{AGRADECIMENTO}

Ao Programa BIC Jr UEMG/CNPq/FAPEMIG, pelas bolsas de Iniciação Científica concedidas.

\section{REFERÊNCIAS}

AL-HARBI, A.H. Faecal coliforms in pond water, sediments and hybrid tilapia Oreochromis niloticus x Oreochromis aureus in Saudi Arabia. Aquaculture Research, v. 34, n. 7, p. 517-524, 2003.

APHA. Standard Methods for the examination of water and wastewaters, 21.ed. Washington: American Public Health Association., 2005.

BRASIL. Ministério da Saúde. Agência Nacional de Vigilância Sanitária. RDC Anvisa-MS no 275, de 21 de outubro de 2002. Diário Oficial da União. Brasília, 23 out. 2003.

BRASIL. Ministério da Saúde. Portaria 2.914, de 12 de dezembro de 2011. Dispõe sobre os procedimentos de controle e vigilância da qualidade da água para o consumo humano e seu padrão de potabilidade. Brasília: Ministério da Saúde, 2011.

CETESB (São Paulo). L5. 406: Coliformes termotolerantes: Determinação em amostras ambientais pela técnica de tubos múltiplos com meio A1 - método de ensaio. São Paulo, 2007.

COELHO, M. I. S. et al. Avaliação da qualidade microbiológica de águas minerais consumidas na região metropolitana de Recife, Estado de Pernambuco. Acta Scientiarum. Health Sciences, v. 32, n. 1, p. 1-8, 2010.

COLVARA, J. G.; LIMA, A.S.; SILVA, W.P. Avaliação da contaminação de água subterrânea em poços artesianos no sul do Rio Grande do Sul. Brazilian Journal of Food Technology, n.2, p. 11-14, jan. 2009.

COSTA, C. L.et al. Avaliação da qualidade das águas subterrâneas em poços do estado do Ceará, Brasil. Semina: Ciências Biológicas e da Saúde, v. 33, n. 2, p. 171-180, 2012.

FARACHE FILHO, A.; DIAS, M. F. F. Qualidade microbiológica de água em garrafões de 20 litros. Alimentos e Nutrição., v.19, n.3, p. 243-248, 2008.

GROTT, S. C.et al. Detecção de cistos de Giardia spp. e oocistos de Cryptosporidium spp. na água bruta das estações de tratamento no município de Blumenau, SC, Brasil. Revista Ambiente \& Água, v. 11, p. 689-701, 2016.

GUSMÃO, I. C. C. P. Avaliação microbiológica, fisíco-química de águas minerais comercializadas em Vitória da Conquista. Revista Eletrônica em Gestão, Educação e Tecnologia Ambiental, v. 18, p. 7$13,2014$.

KASELANI, K. Qualidade da água no meio rural. Veterinária Notícias, v. 23, p. 80-112, 2017.

LECLERC, H.; MOREAU, A. Microbiological safety of natural mineral water. FEMS Microbiology Reviews, v. 26, n. 2, p. 207-222, 2002. 
OLIVEIRA, G. G. C.; PARUSSOLO, L. Qualidade microbiológica da água utilizada para consumo humano em propriedades rurais localizadas no distrito de Piquirivaí, Campo Mourão, Paraná. Revista Uningá, v. 42, p. 39-42, 2014.

PONTARA, A. V.et al. Microbiological monitoring of mineral water commercialized in Brazil. Brazilian Journal of Microbiology, v. 42, n. 2, p. 554-559, 2011.

SABIONI, J. G.; SILVA, I. T. Qualidade microbiológica de águas minerais comercializadas em Ouro Preto, MG. Higiene Alimentar, v.20, n.143, p.72-78. 2006.

SCURACCHIO, P. A. Qualidade da água utilizada para consumo em escolas no município de São Carlos-SP. 2010. 57 p. Dissertação (Mestrado). Universidade Estadual Paulista. Araraquara. 2013. 